\title{
MODEL PEMBELAJARAN BAHASA ARAB TERPADU DI MAPK MAN I SURAKARTA
}

Oleh: Widi Astuti

Dosen STAIMS Yogyakarta

\begin{abstract}
Arabic integrated learning model is one of the main curriculum implementation models are applied to all levels of education, through learning model is expected that students acquire knowledge and master the four skills of Arabic (Istima ', Kalam, qira'ah, kitabah) as a whole and meaningful. This study aimed to analyze the implementation and evaluation of integrated learning Arabic in MAPK MAN I Surakarta. Results from this study is the school is implementing an integrated model of learning Arabic nested types (nested) which combines the various elements of language and language skills contained in the subject matter. During the implementation phase of learning Arabic language shows that teachers have different teaching methods vary in delivering course material. While the Arabic language integrated learning is also implemented on the dorm activities, namely the formation of groups of intensive learning Arabic (Arabic Club). In the implementation of this learning to apply the principles of integrated learning is the theme of the actual and authentic, forming students in groups and create an atmosphere of Arabic and meaningful life outside the formal classroom.
\end{abstract}

Keywords: integrated learning model, Arabic.

\begin{abstract}
Abstrak
Model pembelajaran bahasa arab terpadu merupakan salahsatu model implementasi kurikulum yang diaplikasikan pada semua jenjang pendidikan, melalui model pembelajaran ini diharapkan siswa memperoleh pengetahuan dan menguasai empat keterampilan berbahasa Arab (Istima', Kalam, Qira'ah, Kitabah) secara utuh dan bermakna. Penelitian ini bertujuan untuk menganalisis pelaksanaan dan evaluasi program pembelajaran bahasa Arab terpadu di MAPK MAN I Surakarta. Hasil dari penelitian ini adalah sekolah ini menerapkan model pembelajaran bahasa Arab terpadu tipe nested (tersarang) yaitu memadukan
\end{abstract}


berbagai unsur bahasa dan keterampilan berbahasa yang tertuang dalam materi pelajaran. Pada tahap pelaksanaan pembelajaran menunjukkan bahwa guru bahasa Arab memiliki metode pengajaran yang berbeda-beda dalam menyampaikan materi pelajaran. Sedangkan pembelajaran bahasa Arab terpadu juga dilaksanakan pada kegiatan asrama yaitu terbentuknya kelompok belajar intensif bahasa Arab (Arabic Club). Pada pelaksanaannya pembelajaran ini menerapkan prinsip-prinsip pembelajaran terpadu yaitu mengangkat tema yang actual dan otentik, membentuk siswa secara berkelompok dan menciptakan suasana berbahasa Arab yang hidup dan bermakna diluar kelas formal.

Kata kunci: Model pembelajaran terpadu, bahasa Arab.

\section{A. Pendahuluan}

Model pembelajaran bahasa Arab terpadu merupakan salahsatu model implementasi kurikulum yang diaplikasikan pada semua jenjang pendidikan, baik pendidikan dasar (SD/MI), pendidikan menengah pertama (SMP/MTs), dan pendidikan menengah atas (SMA/MA). Melalui model pembelajaran bahasa Arab terpadu diharapkan siswa memperoleh pengetahuan dan menguasai 4 keterampilan berbahasa arab secara utuh dan bermakna. ${ }^{93}$

Model pembelajaran bahasa Arab terpadu merupakan pembelajaran yang sangat memperhatikan kebutuhan siswa sesuai dengan perkembangannya. Pembelajaran bahasa Arab terpadu juga melibatkan siswa secara aktif dalam proses pembelajaran baik fisik maupun emosionalnya, sehingga siswa dapat menerapkan perolehan belajar siswa melalui pengalaman kongkrit untuk memecahkan masalah-masalah yang nyata

93 Trianto, Model Pembelajaran Bahasa Arab Terpadu (Konsep, Strategi, Dan Implementasinya Dalam Kurikulum Tingkat Satuan Pendidikan (Ktsp) (Jakarta: Bumi Aksara,2010), hlm.6. 
didalam kehidupan sehari-hari. ${ }^{94}$ Berdasarkan kesimpulan diatas menjelaskan bahwa pengalaman belajar siswa menempati posisi penting dalam model pembelajaran bahasa Arab terpadu.

Mengingat pentingnya model pembelajaran bahasa Arab terpadu di lembaga-lembaga pendidikan menimbulkan pertanyaan apakah pelaksanaan model tersebut sudah berjalan sistematis diberbagai pendidikan, khususnya pendidikan menengah atas (SMA/MA).

Dipilihnya MAPK MAN 1 Surakarta sebagai obyek penelitian ini Disertai pertimbangan bahwa lembaga ini telah melaksanakan model pembelajaran bahasa Arab terpadu. Namun apa keunikan-keunikan dalam pelaksanaannya antara lain sebagai mana yang diungkapkan oleh Abdul Mutholib selaku Wa. Ka. Kurikulum MAPK MAN I Surakarta bahwa model pembelajaran bahasa Arab terpadu yang sebenarnya adalah mengkombinasikan materi bahasa Arab (Nahwu, Sarf, Ta'bir, Insya', Muthola'ah, Nasyi'in dan Muhadatsah) dengan memperhatikan empat kemahiran berbahasa Arab dalam kegiatan pembelajaran.

Berdasarkan pemikiran diatas, maka model pembelajaran bahasa Arab terpadu perlu dikaji dari aspek pelaksanaan model pembelajaran bahasa Arab terpadu yang dilaksanakan di MAPK MAN I Surakarta. Hal ini penting untuk memberikan gambaran tentang pembelajaran terpadu yang dapat dijadikan sebagai acuan dan contoh kongkrit dalam menambah hazanah keilmuan dan wawasan tentang pengembangan model pembelajaran bahasa Arab.

\footnotetext{
94 Eko budi susanto, model pembelajaran terpadu dalam http://www.ras-eko.com/2011/05/model-pembelajaran-terpadu.html. akses pada tanggal 7 Desember 2013.
} 


\section{B. Metode Penelitian}

Jenis penelitian yang digunakan dalam penelitian ini adalah penelitian studi kasus dalam arti penelitian ini difokuskan pada kasus (fenomena) yang kemudian dipahami dan dianalisis secara mendalam. ${ }^{95}$ Metode penelitian ini digunakan untuk mendeskripsikan secara holistic dan komperhensif tentang gejala dan peristiwa dalam melaksanakan program model pembelajaran bahasa Arab terpadu di MAPK MAN I Surakarta.

\section{Hasil Dan Pembahasan}

Model pembelajaran bahasa Arab terpadu adalah model pembelajaran yang dilaksanakan dalam rangka memberikan pengalaman belajar siswa dalam memahami tujuan pembelajaran bahasa Arab (istima', kalam, Qira'ah, kitabah) yang terbagi dalam beberapa aspek baik muhadatsah, muthala'ah, imla', maupun insya' secara utuh dan bermakna.

Model pembelajaran terpadu ini memiliki beberapa prinsip antara lain adalah prinsip penggalian tema, prinsip pengelolaan pembelajaran, prinsip evaluasi, dan prinsip reaksi. Prinsip-prinsip tersebut membedakan antara pembelajaran terpadu dengan pembelajaran lainnya.

Depdikbud menjelaskan bahwa pembelajaran terpadu memiliki beberapa karakteristik antara lain pertama, holistic yaitu suatu gejala fenomena yang menjadi pusat perhatian dalam pembelajaran terpadu diamati dan dikaji dari beberapa bidang sekaligus, tidak dari sudut pandang yang terkotak-kotak. Kedua, bermakna yaitu pengkajian suatu fenomena dari berbagai macam

95 Nana Syaodih Sukmadinata, Metode Penelitian Pendidikan. Bandung: Remaja Rosdakarya, 2005. Hlm. 99. 
aspek memungkinkan terbentuknya jalinan antar konsep-konsep yang berhubungan sehingga berdampak pada kebermaknaan materi yang dipelajari.

Ketiga, otentik yaitu pembelajaran terpadu memungkinkan siswa memahami secara langsung prinsip-prinsip dan konsep yang ingin dipelajarinya melalui kegiatan secara langsung. Siswa memahami dari hasil belajarnya sendiri. Keempat, pembelajaran terpadu menekankan keaktifan siswa dalam pembelajaran.

Model-model pembelajaran terpadu menurut Forgarty dalam bukunya how to integrate the curricula ada 10 macam model pembelajaran terpadu antara lain the connected model (model terhubung), the webbed model (model jarring laba-laba), the integrated model (model integrasi), the nested model (model tersarang), the fragmented model (model fragmen), the sequenced model (model terurut), the shared model (model terbagi), the threadred model (model pasang benang), the immersed model (model terbenam), the networked model (model jaringan). ${ }^{96}$

Model pembelajaran bahasa Arab terpadu berbeda dengan model pembelajaran bahasa Arab pada umumnya, Langkahlangkah pembelajaran bahasa Arab terpadu lebih fleksibel karena dapat diadopsi dari berbagai model pembelajaran seperti model pembelajaran langsung (direct instructions), model pembelajaran kooperatif (cooperative learning), model pembelajaran berbasis masalah (problem based instractions) atau kombinasi dari modelmodel pembelajaran.

Adapun model pembelajaran bahasa Arab terpadu yang dilaksanakan di sekolah oleh salahsatu guru bahasa Arab yaitu

96 Novi resmini dalam file.upi.edu/.../model pembelajaran terpadu.pdf diakses pada tanggal 19 November 2015 pada jam 19.30 wib. 
kegiatan diawali dengan salam dan pertanyaan sapaan atau dialog oleh guru bahasa Arab serta siswa menjawabnya dengan bahasa Arab. Kemudian guru menjelaskan topik atau tema "madrasati" yang diangkat melalui contoh-contoh kalimat dari kata benda yang ada di sekolah, seperti; kelas, pohon, lapangan dan sebagainya. Guru juga mengaitkannya dengan bertanya kepada siswa apa bentuk dari lapangan, siswa bingung dalam menjawab dengan bahasa Arabnya, sehingga siswa menjawab pertanyaan guru tersebut dengan kalimat "laa adri yaa ustad".

Guru kemudian menjawabnya dengan mengaitkan bendabenda lain yang sejenis dengan memberikan pertanyaan kembali kepada siswa tentang Ka'bah yang ada di Mekkah yang berbentuk kubus, kemudian siswa mulai memahami kemudian guru menambahi bahwasannya Ka'bah adalah salahsatu bentuk dari kubus, dengan bahasa Arab guru mengaitkanya dengan menjelaskan melalui Qaidah An-nahwiyah bahwasannya Ka'bah memiliki keterkaitan dengan Muka'abun (kubus).

Pada tahap selanjutnya guru menjelaskan langkah-langkah pembelajaran yang harus diikuti siswa dalam pembelajaran bahasa Arab. Guru memberikan tema "madrasati" pada pertemuan ketiga ini, siswa diminta untuk mendengarkan contoh kalimat yang disampaikan guru dan siswa membuat contoh lain dengan tema yang sama. Guru kemudian menginstruksikan siswa untuk mendengar dan mencatat baik kata ataupun kalimat sukar yang terdapat pada bacaan yang diperdengarkan.

Siswa yang telah menyelesaikan tugas sebelumnya dipersilahkan untuk mendemonstrasikannya didepan kelas (muhadatsah). Guru memberikan kesempatan bagi siswa lainnya untuk mengajukan kalimat yang sukar dan siswa lain menjawab. 
Pada kegiatan ini siswa siswa dibimbing untuk mencari secara mandiri melalui bekerjasama dengan siswa lain agar pembelajaran tidak terpusat hanya pada guru (teacher centered).

Setelah siswa aktif mencari dan menemukan jawabannya secara mandiri. Guru menginstruksikan siswa untuk membuat naskah dengan tema madrasati kemudian dipresentasikan bersama teman kelompoknya. Pada tahap ini siswa dituntut untuk belajar kelompok dan aktif diantara siswa-siswa lain, guru menjadi fasilitator didalam kegiatan ini. Setelah guru memberikan waktu untuk berdiskusi, siswa diminta untuk berdemonstrasi hasil diskusi dengan kelompoknya sedangkan siswa lain menyimak.

Pada tahap evaluasi, guru menginstruksikan siswa untuk kegiatan imla' dan insya' dengan menuliskan kalimat sesuai tema yang telah ditentukan dengan memperhatikan struktur kalimat dalam bentuk jumlah ismiyah maupun fi'liyah sesuai dengan Qaidah An-Nahwiyah. Pada kegiatan menulis (Kitabah) ini, siswa yang telah menyelesaikan tugasnya diminta untuk menuliskannya di papan tulis sebagai contoh untuk siswa lainnya.

Pada pembelajaran bahasa Arab terpadu ini, ditekankan pada pembelajaran aktif dengan memposisikan guru sebagai fasilitator. Siswa diberikan kesempatan untuk aktif menggali dan menemukan pengetahuannya sendiri melalui diskusi kelompok.

Adapun pembelajaran bahasa Arab terpadu yang dilaksanakan di asrama berbeda dengan yang ada di kelas formal. Kegiatan ini mempunyai komunitas yang disebut "Arabic Club". Tujuan dari kegiatan ini dimaksudkan agar siswa mampu menggunakan bahasa Arab secara fungsional dikaitkan dengan problem kehidupan sehari-hari. Melalui pembelajaran bahasa 
Arab terpadu ini, siswa dapat berperan aktif dalam mengutarakan maksud dengan belajar berbicara didepan siswa lainnya dan bertukar pendapat tentang tema yang diangkat.

Adapun proses pembelajarannya adalah sebelum masuk dalam pembelajaran inti, guru memberikan pertanyaan singkat yang mengacu pada tema yang akan dibahas. Sebagaimana yang diungkapkan oleh ustad Abdul Mutholib" Maa Ro'yukum 'an AlImtihaan al-Wathoniy?". Adapun pertanyaan singkat yang telah dipaparkan tersebut memberikan maksud agar siswa mempunyai gambaran awal tentang tema yang diangkat dalam pembelajaran bahasa Arab. Pertanyaan tersebut merupakan alat untuk memberikan umpan atau stimulus agar siswa dapat melatih dari aspek Maharah Al-Kalam.

Kegiatan inti dimulai setelah siswa siap untuk menerima materi pelajaran. Pertama, guru memberikan teks berupa ucapan yang harus disimak oleh siswa, sementara guru memberikan penjelasan tema terkait, siswa diharapkan mencatat kosakata baru atau istilah asing. Siswa kemudian diberikan kesempatan untuk bertanya tentang kosakata baru untuk mengetahui maknanya. Guru kemudian membagi siswa kedalam kelompokkelompok untuk berdiskusi.

Adapun pembagian kelompok tersebut sesuai dengan pendapat Slavin bahwasannya pembelajaran kooperatif juga didasarkan pada ide bahwa siswa sebaiknya belajar kelompok dan bertanggungjawab terhadap anggota timnya sebagaimana mereka belajar mandiri. Pembelajaran kooperatif mengklaim bahwa 
belajar kelompok lebih baik daripada belajar mandiri dan dapat dilakukan dalam kelompok kecil. ${ }^{97}$

Setiap kelompok tersebut dibagi menjadi Pro ujian Nasional, Kontra Ujian Nasional, dan kelompok Netral Ujian Nasional. Kemudian guru menginstruksikan kepada siswa untuk membuat minimal 1 paragraf tentang tema yang dibahas dan kegiatan ini menekankan pada Insya' Muwajjahah dalam kemahiran menulis. Siswa kemudian memulai kegiatan debat dan menanggapi pendapat diskusi kelompok lain dan menguatkan pendapat masing-masing kelompok. Kegiatan ini berlangsung atraktif dan siswa antusias. Pada ahir kegiatan guru memberikan kesimpulan dan merefleksi pembelajaran yang telah berlangsung.

Kegiatan ini membutuhkan interaksi antar guru dan siswa maupun siswa dengan siswa secara aktif agar pembelajaran bahasa Arab terpadu lebih bermakna dan kontekstual. Konsep dalam pembelajaran pada kegiatan Arabic Club ini mengacu kepada pendekatan kontekstual yaitu dengan pendekatan berbasis masalah dan pendekatan kooperatif maupun kolaboratif. Metode yang dipakai dalam pembelajaran ini adalah metode langsung, metode eklektik (metode campuran), dan every one is a teacher here. Hal ini dilakukan agar siswa aktif dalam mengemukakan pendapat dan belajar berbicara bahasa Arab. Guru berperan sebagai fasilitator dan motivator dengan konsep student centered ( berpusat pada siswa) pada pembelajaran bahasa Arab terpadu ini.

Berdasarkan hal tersebut, hasil belajar yang diperoleh dari "sharing' antar teman, antar kelompok, dan antara yang belum

97 Abdul Wahab Rosyidi dan Mamlu'atul Ni'mah. Memahami Konsep Dasar Pembeajaran Bahasa Arab (Malang: UIN Maliki Press, 2012), hlm. 43. 
mengetahui kepada yang telah mengetahui. Konsep tersebut sesuai dengan learning community yang menyarankan agar hasil pembelajaran diperoleh dari hasil kerjasama dengan oranglain. ${ }^{98}$

Adapun kelebihan dari pelaksanaan model pembelajaran bahasa Arab terpadu antara lain adalah sebagai berikut;a) siswa mudah memusatkan perhatian pada satu tema tertentu; b) siswa mampu mempelajari pengetahuan dan mengembangkan berbagai kompetensi dasar antar isi mata pelajaran dalam tema yang sama; c) pemahaman materi lebih mendalam dan berkesan; d) kompetensi dasar dapat dikembangkan lebih baik dengan mengkaitkan mata pelajaran lain dengan pengalaman pribadi siswa; e) siswa lebih bergairah belajar karena dapat berkomunikasi dalam situasi nyata.

Adapun kekurangan dari pelaksanaan model pembelajaran bahasa Arab terpadu antara lain adalah sebagai berikut; a) sulit dalam menyeleksi tema, cenderung untuk merumuskan tema yang dangkal dalam pembelajaran. Hal tersebut disebabkan karena dengan keterbatasan waktu tatap muka dalam satu kali pertemuan tidak memungkinkan bagi guru dan siswa membahas materi secara mendalam dan keseluruhan; b) guru lebih memusatkan perhatian pada kegiatan daripada pengembangan konsep.

\section{Penutup}

Pada tahap pelaksanaan pembelajaran bahasa Arab terpadu ini menunjukkan bahwa masing-masing guru bahasa Arab memiliki metode pengajaran yang berbeda-beda dalam

98 Muhammad Hafidz, Teknik Pengajaran Keterampilan Berbahasa Upaya Mewujudkan Pelajar Bahasa Yang Aktif (Lisania:Jurnal Ilmu Dan Pendidikan Bahasa Arab, Vol.2 No. 1, 2011), hlm. 139. 
menyampaikan materi. Adapaun pembelajaran bahasa Arab yang dilaksanakan di kelas dapat diketahui bahwa sekolah ini menerapkan model pembelajaran bahasa Arab terpadu tipe Nested (tersarang) yaitu memadukan unsure-unsur bahasa yang tertuang dalam pelajaran (istima', takbir, insya', muhadatsah, nasyiin, nahwu dan sharf).

Sedangkan pembelajaran bahasa Arab terpadu juga dilaksanakan di kegiatan asrama yaitu terbentuknya kelompok belajar intensif bahasa Arab (Arabic Club). Pada pelaksanaannya pembelajaran ini menerapkan prinsip-prinsip pembelajaran terpadu yaitu mengangkat tema actual dan otentik, membentuk siswa berkelompok dan menciptakan suasana bahasa Arab yang hidup dan bermakna diluar kelas formal. 


\section{DAFTAR PUSTAKA}

Resmini, Novi. File.Upi.Edu/.../Model Pembelajaran Terpadu. Pdf Diakses Pada Tanggal 19 November 2015 Pada Jam 19.30 Wib.

Rosyidi, Abdul Wahab dan Mamlu'atul Ni'mah. Memahami Konsep Dasar Pembeajaran Bahasa Arab. Malang: UIN Maliki Press, 2012.

Susanto, Eko Budi. Model Pembelajaran Terpadu Dalam Http://Www.Ras-Eko.Com/2011/05/Model-PembelajaranTerpadu.Html. Akses Pada Tanggal 7 Desember 2013.

Sukmadinata, Nana Syaodih. Metode Penelitian Pendidikan. Bandung: Remaja Rosdakarya, 2005.

Trianto. Model Pembelajaran Bahasa Arab Terpadu (Konsep, Strategi, Dan Implementasinya Dalam Kurikulum Tingkat Satuan Pendidikan (KTSP). Jakarta: Bumi Aksara, 2010.

Trianto. Model Pembelajaran Terpadu dalam Teori dan Praktek. Jakarta: Prestasi Pustaka, 2007. 